\title{
THE FEMALES OF ENALLAGMA LATERALE MORSE AND RECURVATUM DAVIS (ODONATA : COENAGRIONIDAE)
}

\author{
BY ROBERT H. GIBBS, JR. \\ Department of Conservation \\ Cornell University, Ithaca, New York
}

Of the 23 northeastern members of the genus Enallagma, the females of piscinarium, laterale, and recurvatum have not been described. E. piscinarium is apparently known only from the type male. Although males of laterale have been taken in several localities, the female remains unrecorded. The female of recurvatum may have been collected, but references to it are quite misleading. In the original description of the species by Davis (1913) the female is supposedly described, but the description is quite inadequate and not diagnostic. Byers, in his key (1927), does not distinguish it from $E$. hageni other than by its comparative rarity. Garman (1927) stated that "all supposed females thus far examined have proved to belong to other species."

Systematic collecting on Cape Cod, Massachusetts, has resulted in the finding of tandem pairs of both laterale and recurvatum. In addition, Thomas W. Donnelly has allowed me to examine some collections sent to him by Mr. Roy Latham from Riverhead, Long Island, New York, which contained two females of recurvatum and one of laterale. The following descriptions are based on these Cape Cod and Long Island specimens.

For suggestions during the preparation of this manuscript, I wish to express appreciation to E. M. Walker, L. K. Gloyd, M. J. Westfall, Jr., T. W. Donnelly, H. E. Evans, and J. G. Franclemont.

\section{Enallagma laterale Morse. Female}

Psyche 7: 274. 1895

Color: Olivaceous, washed with light blue, and black.

Head: Dorsum black; pale frontal margin reaching bases 
of antennae; postocular spots elongate, comma-shaped, connected by a narrow, pale occipital bar, not quite reaching the ocular margins; face pale except postclypeus black with pale margins; mouthparts and rear of head pale; antennae black, apices of first and second segments pale. Prothorax: Front lobe pale bordered with black; middle lobe black dorsally, pale laterally, a dorsolateral pale spot present on each side and variable in size, a pair of prominent dorsolateral pits present near the caudal margin; hind lobe black with pale lateral margins, caudal margin convex and entire.

Pterothorax: Pale with black middorsal stripe occupying about half the mesepisternum and slightly narrowed posteriorly; black humeral stripe slightly narrower than pale antehumeral stripe, of about constant width throughout, but with a slight widening posterior to the mesinfraepisternum; first lateral stripe represented by a mere posterior vestige; metapleural suture covered by a thin second lateral stripe, which expands posteriorly into a spot; humeral and middorsal stripes connected posteriorly by the black of the antealar carina and sinus, which fades slightly laterad of the humeral stripe. Coxae and trochanters entirely pale. Femora and tibiae pale, each with a black external stripe for almost the entire length; tarsi pale, each with distal end of third segment dark; spines of legs black; claws pale with black tips.

Mesostigmal laminae: Widest in mesal half; a closed mesal concavity present, deepest posteriorly; the entire lateral half twisted and upturned at an angle of 60 degrees or more; most of lateral half pale; separated from the thoracic depression by a posterior groove for its lateral half only.

Wings: Venation black or dark brown; pterostigma light brown. $\mathrm{M}_{2}$ arises between the 4 th and 5th postnodal crossveins in the front wings, between the $3 \mathrm{rd}$ and 4 th in the hind wings; postnodals 9-12 in front wings, 8-10 in hind wings; $M_{1 a}$ arises at about the level of the 8th postnodal in both wings.

Abdomen: Pale with black as follows: Segment one, a squared middorsal spot on basal half, a small apical spot 
on each side; segment 2, entire dorsum, widened slightly toward apex, connected to a narrow apical ring; segments $3-7$, entire dorsum, abruptly constricted basally, slightly widened anteapically, connected with a narrow apical ring; segment 8 , entire dorsum, widened gradually from base to apex; segments 9 and 10, entire dorsum. Midventral sternal carinae black on 1-8. Anal appendages and valves and styli of ovipositor pale; apex of each valve of ovipositor, to base of stylus, extends not quite to apex of segment 10 excluding appendages. Ventral spine of segment 8 black to dark brown, sharp.
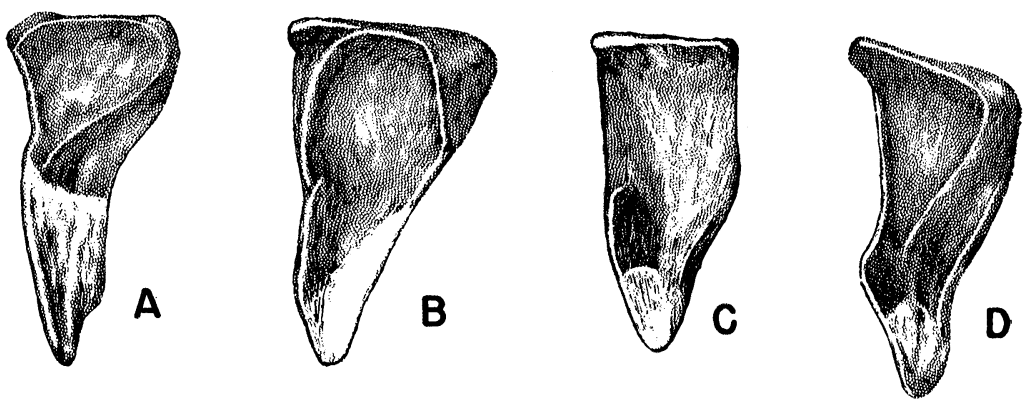

Figure 1. Left mesostigmal lamina of Enallagma females in dorsolateral aspect. A. laterale. B. recurvatum. C. davisi. D. minusculum. ca. $35 x$.

Measurements: Total length to apex of segment 10, excluding appendages: $24.8-28.0 \mathrm{~mm}$.; length of abdomen: 20.0-22.7 mm.; length of front wing: 14.5-17.8 mm.; length of hind wing: 15.4-16.3 mm. The two Cape Cod specimens are larger; the Long Island specimen is represented by the smaller extreme in each case.

Described from two specimens captured in tandem with males by the writer at Jabinette's Pond, West Yarmouth, Massachusetts, on June 13, 1953, and one specimen from Riverhead, Long Island, New York, caught on May 29, 1953, by Mr. Roy Latham.

Enallagma recurvatum Davis. Female

Jour. N. Y. Ent. Soc. 21 : 15-16. 1913

Color: Olivaceous, washed with light blue, and black. 
Head: Dorsum black; pale frontal margin not quite reaching bases of antennae; postocular spots commashaped, isolated from the light occipital carina, not quite reaching ocular margins; face pale except postclypeus black and pale lateral edges; mouthparts and rear of head pale; antennae black, apices of first and second segments pale.

Prothorax: Front lobe pale bordered with black; middle lobe black dorsally, pale laterally, a dorsolateral pale spot either present on each side and variable in size, or absent, and a pair of prominent dorsolateral pits present near the caudal margin; hind lobe black with pale lateral margins, caudal margin convex and entire.

Pterothorax: Pale with black middorsal stripe occupying slightly more than half the mesepisternum, somewhat narrowed posteriorly; humeral black stripe slightly wider than the pale antehumeral stripe, widened at the mesinfraepisternal suture, narrower on the mesinfraepisternum; first lateral stripe absent or a mere vestige; second lateral stripe a fine line on the metapleural suture, widened posteriorly into a spot; middorsal and humeral stripes connected posteriorly by the black of the antealar carina and sinus, which continues laterad to the region of the first lateral stripe. Coxae and trochanters entirely pale. Femora and tibiae pale, each with a wide black lateral stripe covering most of their lateral surface; tarsi pale, each with tip of third segment dark; spines of legs black; claws pale with black tips.

Mesostigmal laminae: Mesal edge at about a 30 degree angle to middorsal carina; mesal half much wider than lateral half; postero-mesal corner much thickened; a deep depression near mesal margin; anterior margin of lateral portion upturned; lateral end with a variable, usually small, light spot.

Wings: Venation black or dark brown; pterostigma light brown. $\mathrm{M}_{2}$ arises between the 4 th and 5th or 5th and 6th postnodal crossveins in the front wings, between the 3rd and 4 th or 4th and 5th in hind wings; postnodals 9-11 in front wings, 8-10 in hind wings, the majority having 
11 and $9 ; \mathrm{M}_{1 \mathrm{a}}$ arises at about the level of the 7 th to 9 th postnodal crossvein in the front wings, about the 7th or 8th in the hind wings, the majority arising at the 8th in both wings.

Abdomen: Pale with black as follows: Segment one, a middorsal basal spot and a lateral apical transverse dash; segment 2, entire dorsum, constricted or narrower in anterior half, connected with an apical ring; segments 3-7, entire dorsum, abruptly constricted basally, slightly widened anteapically, connected with an apical ring; segment 8, a narrow middorsal line abruptly widened to cover apical dorsum; segments 9 and 10, entire dorsum. Midventral sternal carinae black on 1-8. Anal appendages and valves and styli of ovipositor pale; apex of each valve of ovipositor, to base of stylus, extends not quite to apex of segment 10 excluding appendages. Ventral spine of segment 8 black or dark brown, sharp.

Measurements: Total length to apex of segment 10, exclusive of appendages : 26.8-28.2 mm.; length of abdomen: 21.0-22.2 mm.; length of front wing: 16.1-18.0 mm.; length of hind wing: 14.7-16.9 mm. Taken from four Cape Cod specimens and one from Long Island. The Long Island specimen is represented in each measurement by the smaller extreme.

Described from 11 specimens from the following localities: Flax Pond, North Falmouth, Mass., June 17, 1951 (3), June 16, 1953 (5), and Jabinette's Pond, West Yarmouth, Mass., June 13, 1953 (1), all collected by the writer; and Riverhead, Long Island, New York, May 29, 1953 (1), June 2, 1953 (1), collected by Mr. Roy Latham.

Key to Females of Ten Species of Enallagma

Based Principally on Mesostigmal Laminae

In the key which follows, the females of ten species of Enallagma are compared. These ten comprise those which might be confused for one reason or another, or which may be closely related to laterale or recurvatum. Relationships among the species of Enallagma are difficult to determine and, to date, have been largely based on the form 
of the anal appendages of the male. It has been almost impossible to divide the females into logical groups. Mention of the males of the species being compared, then, may make clearer the reason for comparing their females.

Enallagma laterale would appear, from gross examination of the male genitalia, to be close to $E$. piscinarium, $E$. davisi, and $E$. boreale, and perhaps to $E$. minusculum (Westfall, 1943). In these species the superior anal appendage is shorter than segment 10 and ranges from bluntly rounded to deeply, but narrowly, cleft. $E$. minusculum is most like davisi, but the lower arm of the superior anal appendage of the former appears prominently circular in lateral view.

The male of $E$. recurvatum bears a superficial resemblance to $E$. vernale, but the latter species is believed by Mrs. Gloyd (1943) and by Walker (1953) to be more closely related to cyathigerum. The recurved superior anal appendages of recurvatum are somewhat similar to those of E. hageni, which, however, are straight as viewed laterally. Both laterale and davisi males are characterized by a lateral black mark on the eighth abdominal segment. Several recurvatum from Cape Cod also show this mark, although it is not commonly present.

The caudal lamellae of the nymphs of $E$. ebrium and $E$. geminatum resemble those of laterale (Howe, 1921), indicating possible relationship. The nymph of recurvatum is unknown, and that of laterale has never been adequately described.

The form of the mesostigmal laminae may prove to be indicative of relationships among the females of Enallagma. At any rate, the laminae are by far the best means for identifying the species. If Byers (1927) had possessed females of both hageni and recurvatum, he could have recognized them both immediately by a glance at the laminae. In the key this character will play a prominent part. For illustrations of the mesostigmal laminae of most of the keyed species, I recommend the beautiful plates in Walker (1953). Those of laterale, recurvatum, and davisi (from the allotype) are figured in the present paper, along with that of minusculum. The latter is in- 
cluded because Walker's illustration is somewhat deceptive. The resemblance is obvious, but I have found the lateral ends bluntly pointed, not rounded, and the diagonal ridge which runs antero-laterally from the postero-mesal region is diagnostic.

1 - Lamina more than half as wide as long

- Lamina less than half as wide as long

2(1) Lamina widest mesally, gradually narrowing laterally for two-thirds of length, rapidly narrowing in lateral one-third to form an antero-lateral blunt point, postero-lateral edge not curled upward; dorsum of abdominal segment one entirely black, connected to an apical ring. ebrium

- Lamina widest about midway to lateral end, the postero-lateral edge curled upward, often extremely so, a blunt point formed antero-laterally; dorsum of segment one with a black basal spot and an apical spot on each side. hageni

3(1) Lamina with a mesal enclosed concavity formed by the high antero-mesal corner and the raised or thickened postero-mesal edge

- No such concavity present; edges may be curled to form a shallow basin or cavity may be formed by anterior corner and be open posteriorly ...................8

4 (3) Postero-mesal margin of lamina tilted ...... vernale

- Postero-mesal margin of lamina not tilted, but may be thickened

5 (4) Lamina twisted so that entire lateral half is greatly tilted

- Entire lateral half of lamina not up tilted; anterolateral margin may be raised

6(5) Twisted lateral portion of lamina bent posteriorly; lamina well-demarcated from thorax by a posterior groove for its entire length; prothoracic pits absent; segment one with dorsum entirely black, connected to apical ring; black of segment 8 not narrowed; black of segments 9 and 10 extending far laterad minusculum 
- Twisted lateral portion of lamina not bent posteriorly; lamina definitely demarcated only in lateral half; prothoracic pits present; segment one with a black basal spot, lateral apical spots; segment 8 with black slightly narrowed anteriorly; black of segments 9 and 10 not extending much beyond a mid-lateral point laterale

7 (5) Mesal edge of lamina at about 30 degree angle to mid-dorsal carina; postero-mesal corner much more thickened than antero-mesal, posterior edge broadly curved in mesal half, mesal half much broader than lateral half; pit in frame rather wide; prothoracic pits present; black of segment 8 constricted in basal half, no lateral stripe present on 2 or 8 ..... recurvatum

- Mesal edge of lamina nearly parallel to mid-dorsal carina; antero-mesal corner more thickened than postero-mesal, posterior edge nearly straight, mesal half not greatly broader than lateral half; pit in frame rather small; prothoracic pits absent (sometimes a deceptive set of shallow areas present); a lateral black stripe present on segment 2; black of segment 8 narrow dorsally, a black lateral stripe present, the two black portions enclosing a blue spot on each side geminatum

8(3) Lamina nearly flat except tilted antero-lateral margin; prothoracic pits present davisi

- Lamina not flat; anterior open concavity present; prothoracic pits absent

9 (8) Mesal edge of lamina at about a 30 degree angle to mid-dorsal carina; postero-mesal margin sharply delimited from the thorax by a groove. cyathigerum

- Mesal edge of lamina nearly parallel to mid-dorsal carina; postero-mesal margin not clearly demarcated from thorax boreale 


\section{Literature Cited}

Byers, C. Francis

1927. Key to the North American species of Enallagma with a description of a new species. Trans. Am. Ent. Soc. 53: 249-260.

Davis, William T.

1913. Dragonflies of the vicinity of New York City with a description of a new species. Jour. N. Y. Ent. Soc. 21: 11-29.

Garman, Philip

1927. Guide to the insects of Connecticut. Part V. The Odonata or dragonflies of Connecticut. State Geol. and Nat. Hist. Surv. Bull. 39. Pp. 331.

Gloyd, Leonora $K$.

1943. Enallagma vernale, a new species of Odonata from Michigan. Occ. Pap. Mus. Zool. Univ. Mich. 479: 1-8.

Howe, R. Heber, JR.

1921. Manual of the Odonata of New England. Nymphs. Mem. Thoreau Mus. Nat. Hist. II: 103-115.

Morse, Albert P.

1895. New North American Odonata. II. Psyche 7: 274-275.

WaLKer, Edmund M.

1953. The Odonata of Canada and Alaska. Vol. I. Pp. xi +292 . Univ. Toronto Press.

Westfall, Minter J., JR.

1943. Enallagma davisi, a new species from Florida. Ent. News 54: 103-108. 

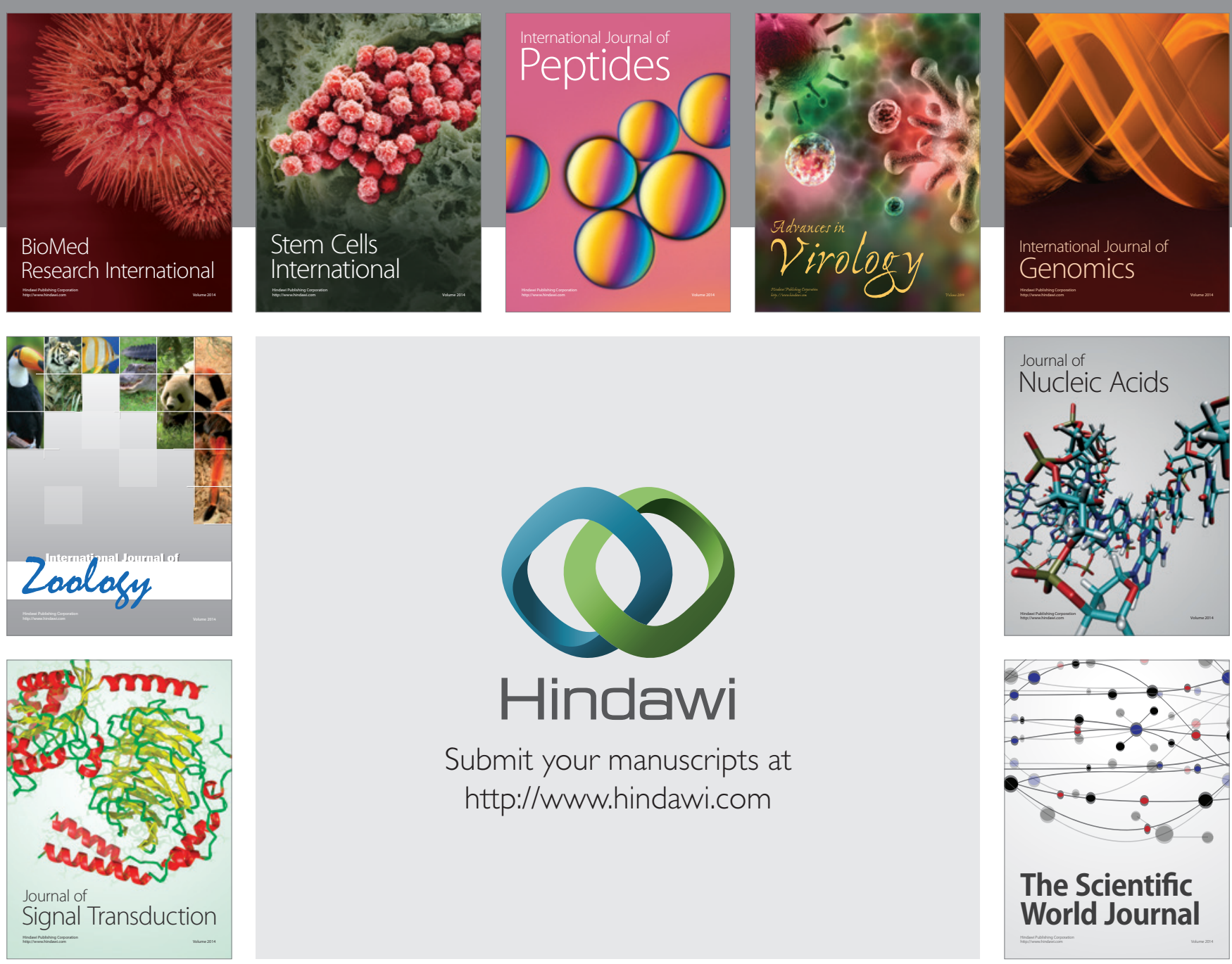

Submit your manuscripts at

http://www.hindawi.com
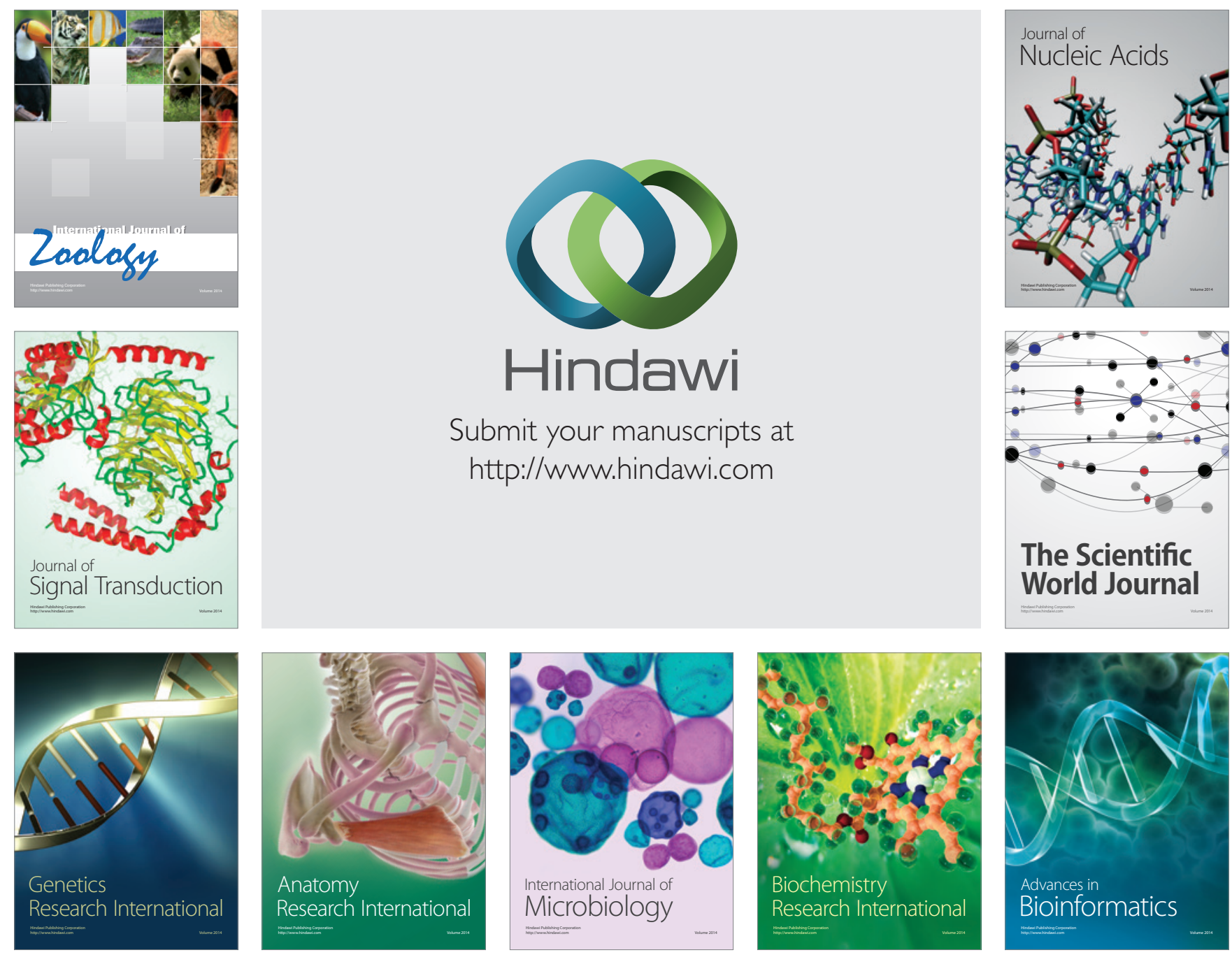

The Scientific World Journal
